\title{
Factors affecting circulating levels of peptide $Y Y$ in humans: a comprehensive review
}

\author{
Jamie A. Cooper* \\ Department of Nutritional Sciences, Texas Tech University, Lubbock, TX, USA
}

\begin{abstract}
As obesity continues to be a global epidemic, research into the mechanisms of hunger and satiety and how those signals act to regulate energy homeostasis persists. Peptide YY (PYY) is an acute satiety signal released upon nutrient ingestion and has been shown to decrease food intake when administered exogenously. More recently, investigators have studied how different factors influence PYY release and circulating levels in humans. Some of these factors include exercise, macronutrient composition of the diet, body-weight status, adiposity levels, sex, race and ageing. The present article provides a succinct and comprehensive review of the recent literature published on the different factors that influence PYY release and circulating levels in humans. Where human data are insufficient, evidence in animal or cell models is summarised. Additionally, the present review explores the recent findings on PYY responses to different dietary fatty acids and how this new line of research will make an impact on future studies on PYY. Human demographics, such as sex and age, do not appear to influence PYY levels. Conversely, adiposity or BMI, race and acute exercise all influence circulating PYY levels. Both dietary fat and protein strongly stimulate PYY release. Furthermore, MUFA appear to result in a smaller PYY response compared with SFA and PUFA. PYY levels appear to be affected by acute exercise, macronutrient composition, adiposity, race and the composition of fatty acids from dietary fat.
\end{abstract}

Key words: Satiety: Exercise: Dietary fatty acids: Obesity

\section{Introduction}

The prevalence of obesity in the USA continues to be a public health concern, with approximately two-thirds of the adult population being classified as overweight and $35 \%$ being classified as obese ${ }^{(1,2)}$. While these rates are highest in the USA, the UK and all of Europe also have a high prevalence of adults being classified as overweight (range $38-60 \%$ ) or obese (approximately $20-25 \%$ of

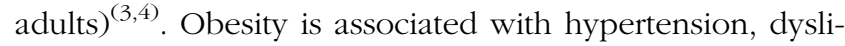
pidaemia, CVD, stroke, diabetes mellitus, musculoskeletal disorders, certain cancers and an increased risk of disability. Thus, obese individuals have an increased risk for morbidity and mortality ${ }^{(5,6)}$. The growing epidemic of obesity is attributed primarily to lifestyle factors, specifically by decreases in physical activity, increases in total energy and fat intake, and the interaction of these environmental factors with genetic susceptibility ${ }^{(7)}$.

To maintain body weight, average daily energy intake must be matched with average daily energy expenditure so that an individual is in energy balance. Only when energy balance is achieved can the prevention of future weight gain occur. Although meal-to-meal and day-to-day variations are quite large, over time, energy intake is matched to energy expenditure and body-weight changes are minimal or modest over periods of months and years $^{(8)}$. Consequently, it is thought that energy intake must also be well regulated. Not all research supports this idea, though, and it has recently been an issue of debate among scientists, with some supporting the notion that energy balance is not tightly regulated ${ }^{(9,10)}$. One measure of support for this long-term regulation over energy balance is the history of weight gain in adults. Average annual weight gain since the early $1960 \mathrm{~s}$ (which was the beginning of the obesity epidemic) is a modest $0 \cdot 3 \mathrm{~kg}^{(11,12)}$. This equates to an energy surplus of about $29 \mathrm{~kJ} / \mathrm{d}(7 \mathrm{kcal} / \mathrm{d})$. This is, of course, without correcting for a greater energy expenditure as body weight increases which would result in a larger energy surplus if assessed over a period of decades where substantial weight gain is occurring ${ }^{(9)}$. Regardless of the amount of energy surplus, it is also important to remember that several factors aside from satiety hormones affect what

Abbreviations: ARC, arcuate nucleus; CCK, cholecystokinin; NPY, neuropeptide Y; POMC, pro-opiomelanocortin; PYY, peptide YY. 
we eat including emotions, social factors, time of day, convenience and cost $^{(13)}$.

During the past 20 years, research into the mechanisms of hunger and satiety has identified numerous circulating hormones that are thought to play a role in the overall control of hunger and satiety and thus act to regulate total energy intake, and to a lesser extent energy expenditure, which ultimately affects body weight ${ }^{(14)}$. One such satiety hormone, peptide YY (PYY), has been assessed recently in a number of studies that are seeking to determine what nutrients, human demographics, or type of physical activity make an impact on circulating PYY levels to the greatest extent. There are two purposes of the present review: (1) to summarise the recent literature on the role of PYY in regulating energy balance and the factors that affect its release and circulating levels within the human body; and (2) to examine the emerging evidence on the effect of dietary fatty acid composition on PYY release and circulating levels in humans.

\section{Discussion \\ Structure of peptide $Y Y$}

PYY was first identified in the small intestine by Tatemoto \& Mutt in $1980^{(15)}$. It is a thirty-six-amino acid peptide that has both an amino acid terminal tyrosine and a carboxyl terminal tyrosine amide and belongs to the pancreatic polypeptide family. Its tertiary structure consists of a polyproline helix and $\alpha$-helix connected by a $\beta$-turn resulting in a characteristic U-shaped peptide ${ }^{(16)}$. PYY is secreted mostly from the endocrine L-cells of the ileum, colon and rectum (with highest concentrations in the colon and rectum), although PYY mRNA has been identified in the stomach, duodenum, jejunum, pancreas and brainstem $^{(17,18)}$. Its secretion is initiated either by direct luminal contact of nutrients with the endocrine cells or indirectly through neurohumoral signals ${ }^{(19)}$. These neurohumoral signals are hormones that are released into the blood by neuroendocrine cells that are stimulated through nerve impulses. PYY exists in two forms: $\mathrm{PYY}_{1-36}$ and $\mathrm{PYY}_{3-36}$. $\mathrm{PYY}_{3-36}$ is produced by the enzyme dipeptidyl peptidase-IV which hydrolyses PYY at the Pro $^{2}-\mathrm{Ile}^{3}$ bond of the $\mathrm{NH}_{2}$ terminus ${ }^{(20)}$. $\mathrm{PYY}_{1-36}$ binds and activates all five $\mathrm{Y}$ receptors $(\mathrm{Y} 1-\mathrm{Y} 5)$. If the first two amino acids at the N-terminal are removed, the receptor selectivity changes because $\mathrm{PYY}_{3-36}$ only has a high affinity for the Y2 receptor ${ }^{(21)}$. While both forms are biologically active at all times, $\mathrm{PYY}_{3-36}$ is the main storage and circulating form of $\mathrm{PYY}^{(14)}$ and is thought to more actively control food intake ${ }^{(22)}$.

\section{Functions of peptide $Y Y$}

PYY has multiple functions including slowing gastric emptying and gastrointestinal motility, inhibiting the secretion of gastric acid, gallbladder contractions, and pancreatic exocrine enzymes, and the most well-documented function of regulating food intake ${ }^{(19,23)}$. Intravenous infusions of PYY reduce appetite and energy intake in healthy human subjects, suggesting that PYY plays a role in regulating satiety $^{(21,24,25)}$. Circulating levels of PYY are low in the fasted state and both the 3-36 and 1-36 forms increase rapidly upon nutrient ingestion ${ }^{(14)}$. While it is well known that PYY is released in response to nutrient intake, it is also released by gastric acid, cholecystokinin (CCK), and infusion of bile acids into the ileum or colon as shown in animal studies ${ }^{(26,27)}$. Finally, PYY secretion is affected by things other than food consumption such as intestinal peristalsis and intraluminal nutrients ${ }^{(28,29)}$. Much like ghrelin and CCK, PYY is not released by gastric distension ${ }^{(30)}$.

Plasma PYY levels increase within $15 \mathrm{~min}$ after nutrient consumption, peak at about 60-90 min, and remain elevated for up to $6 \mathrm{~h}^{(31)}$. Postprandial levels have been shown to be proportional to meal size ${ }^{(31)}$. The initial increase in PYY concentration occurs before food is able to reach the L-cells of the small intestine, indicating that there is a neural or endocrine mechanism that involves cephalic phase-mediated PYY release ${ }^{(32)}$. PYY release becomes greater when the nutrients arrive at the endocrine L-cells and the sustained release of PYY for up to $6 \mathrm{~h}$ postprandially is thought to be due to the direct effects of the intraluminal gut contents on the L-cells ${ }^{(25)}$. PYY responds to all three macronutrients, with the strongest stimulus being with either fats or proteins (described in more detail below) ${ }^{(33)}$. Appetite-suppressant effects of duodenal lipids are dependent on fat digestion, so fat digestion may also be a prerequisite for fat-induced stimulation of $\mathrm{PYY}^{(34)}$. Indeed, blocking the hydrolysis of long-chain fatty acids abolishes the typical PYY postprandial response, probably due to a lack of CCK release ${ }^{(29)}$.

Other foods or substances have also been tested for potential PYY responses. PYY has been shown to increase following ingestion of decaffeinated coffee ${ }^{(35)}$, but does not change in response to alcohol ingestion in adult men and women ${ }^{(36)}$. Additionally, it has recently been suggested that artificial sweeteners could stimulate the release of PYY because of two sweet taste receptors (T1r2 and T1r3) that are co-localised with PYY in enteroendocrine L-cells. However, ingestion of the artificial sweetener sucralose does not lead to changes in circulating PYY levels ${ }^{(32)}$.

\section{Mechanism of action for peptide $Y Y$}

Similar to other peripheral hunger or satiety signals, PYY acts on the arcuate nucleus (ARC) of the hypothalamus by targeting the neuropeptide Y (NPY) neurons ${ }^{(37)}$. PYY is able to cross the blood-brain barrier freely by a nonsaturable mechanism ${ }^{(38,39)}$. This non-saturable mechanism implies that there is no point at which saturation of that mechanism occurs, so there is no limit to the amount of 
PYY that can cross that blood-brain barrier. Within the ARC, there are two subsets of neurons that integrate signals and influence energy homeostasis. These neurons are the NPY/agouti-related peptide (AgRP) neurons and the pro-opiomelanocortin (POMC)/cocaine- and amphetamineregulated transcript (CART) neurons ${ }^{(40,41)}$. The NPY/AgRP neurons are classified as orexigenic (appetite stimulating) while the POMC/CART neurons are classified as anorexigenic (appetite suppressing) ${ }^{(42)}$. In the ARC, PYY is a potent agonist of both the $\mathrm{Y} 1$ and $\mathrm{Y} 2$ receptors and can also bind to the $\mathrm{Y} 5$ receptor whereas $\mathrm{PYY}_{3-36}$ has a very high affinity for the Y2 receptor ${ }^{(37)}$. The Y2 receptor of NPY is a 381-amino acid, seven transmembrane-spanning, G-protein-coupled receptor ${ }^{(43)}$. In humans, the Y2 receptor is found through the entire central nervous system and Y2 mRNA in the hypothalamus is localised in the ARC, preoptic nucleus, and dorsomedial hypothalamus. Over $80 \%$ of the NPY neurons co-express $\mathrm{Y} 2$ receptor $\mathrm{mRNA}$ in the $\mathrm{ARC}^{(43)}$. The brainstem is also a site of $\mathrm{Y} 2$ receptor mRNA which includes the nucleus tractus solitarius ${ }^{(19)}$.

Agonists of the $\mathrm{Y} 2$ receptor, or $\mathrm{Y} 2$ receptor injections, show a reduction in the release of NPY. Conversely, Y2 antagonists increase NPY release ${ }^{(19)}$. The importance of the $\mathrm{Y} 2$ receptor in feeding regulation has been examined with Y2 agonist injections into the ARC of rats, which results in a reduction in food intake that lasts for up to $8 \mathrm{~h}$ post-administration ${ }^{(19)}$. PYY has agonistic properties on $\mathrm{Y} 2$ receptors, so binding to those receptors leads to an inhibition of food intake ${ }^{(25)}$. Further, Y2 receptor knockout mice are unable to inhibit food intake in the presence of PYY(44).

It has also been suggested that $\mathrm{PYY}_{3-36}$ is associated with the POMC neurons within the ARC of the hypothalamus. Agonists of the $\mathrm{Y} 2$ receptor show an increase in the release of $\alpha$-melanocyte stimulation hormone $(\alpha-\mathrm{MSH})$ from POMC neurons. Further, Batterham et al. ${ }^{(24)}$ examined the electrophysiological response of the POMC neurons in mice. Through measurements of depolarisation and inhibitory postsynaptic currents, they discovered that $\mathrm{PYY}_{3-36}$ was able to inhibit NPY neurons, which led to a decrease in the $\gamma$-aminobutyric acid (GABA)-mediated inhibition of POMC neurons ${ }^{(24)}$. Therefore, the effect of PYY on POMC neurons may be indirectly through decreased GABA as a result of NPY inhibition. Interestingly, a different study by Acuna-Goycolea \& van den $\mathrm{Pol}^{(45)}$ showed that $\mathrm{PYY}_{3-36}$ actually inhibited both POMC and NPY neurons in a dose-dependent manner. Since POMC neurons are anorexigenic, this would go against the established satiating effect of PYY in the body. However, it appears that PYY may more strongly inhibit NPY cells, and that the NPY inhibition is strong enough to override any possible inhibition in the POMC neurons. Further evidence that POMC is not the primary regulator of PYY-responsive satiety has been shown with reduced food intake in response to $\mathrm{PYY}_{3-36}$ administration in POMC knock-out mice ${ }^{(46)}$. Therefore, it appears that inhibition of NPY via the Y2 receptor is the primary way in which $\mathrm{PYY}_{3-36}$ acts as an anorexigenic peptide.

\section{Exogenous administration of peptide $Y Y$}

PYY was first recognised as a satiety signal after studies clearly showed that exogenous administration of PYY affected certain neurons in the ARC and reduced body weight when given chronically. Studies in both human and animal models show that peripheral administration of PYY results in large decreases in food intake ${ }^{(14,24)}$. Additionally, in rodents, injection of $\mathrm{PYY}_{3-36}$ directly into the ARC inhibits release of NPY, stimulates release of $\alpha-\mathrm{MSH}$, and inhibits food intake ${ }^{(19,24)}$. In another rodent study, $\mathrm{PYY}_{3-36}$ administered at a dose that is representative of peak postprandial plasma levels resulted in decreased food intake during the dark phase (the dark phase is when rodents are awake, so they are moving around and eating during this phase). The rodents also received twice-daily doses of $\mathrm{PYY}_{3-36}$ for $8 \mathrm{~d}$, which resulted in a significant reduction in food intake and reduced bodyweight gain when compared with the saline control ${ }^{(19)}$.

The satiating effects of PYY have been clearly shown in human subjects as well. Batterham et al. ${ }^{(24)}$ gave a 90-min infusion of $\mathrm{PYY}_{3-36}$ to twelve normal-weight subjects (six men and six women). The dose was designed to mimic normal postprandial responses. They reported a decreased energy intake of $36 \%$ at a free buffet meal following PYY administration $v$. the saline control. Further, food diaries showed that food intake remained decreased for up to $12 \mathrm{~h}$ following a PYY infusion, but did not alter food intake from 12 to $24 \mathrm{~h}$ after administration. The total reduction in energy intake over a $24 \mathrm{~h}$ period was $33 \%{ }^{(24)}$. Exogenous administration of PYY was also used to study its effects in lean and obese adults. Energy intake at an ad libitum buffet $2 \mathrm{~h}$ after $\mathrm{PYY}_{3-36}$ infusions was decreased by $31 \%$ in normal-weight adults and $30 \%$ in obese adults ${ }^{(25)}$. The aforementioned findings for a reduction in food intake following exogenous administration of PYY in both normal-weight and obese adults have been confirmed in several other studies ${ }^{(47-50)}$. Together, these studies provide further evidence of the acute or short-term regulation of $\mathrm{PYY}_{3-36}$ on energy intake in both human and rodent models.

\section{Role of peptide YY in appetite control}

While the aforementioned paragraphs provide clear evidence on the response of PYY to nutrient ingestion, as well as the impact that exogenously administered PYY has on decreasing food intake and body weight, the role of endogenously produced PYY in controlling overall appetite is less frequently studied and less conclusive. Some of the controversy over the role of endogenous PYY on appetite control may stem from some reports that PYY levels are not always correlated with subjective 
ratings of hunger and fullness ${ }^{(51-53)}$. Importantly, though, there is also evidence that visual analogue scales may not be a good indicator of subjective feelings of hunger and fullness ${ }^{(54)}$. This limits the ability to determine whether or not PYY directly affects subjective feelings of hunger and fullness. To further complicate the issue, other studies have shown that plasma PYY levels are positively correlated with ratings of fullness and inversely correlated with ratings of hunger ${ }^{(55,56)}$.

The other area of research that generates questions about the role of endogenous PYY levels on appetite control is the relationship between circulating PYY levels and daily food intake or intake at an ad libitum buffet. In rodents, circulating PYY levels following test meals of varying protein content were inversely correlated with food intake ${ }^{(55)}$. This suggests at least a partial role of PYY in appetite regulation. Conversely, in human subjects, neither fasting nor postprandial PYY levels were associated with ad libitum food intake over a $24 \mathrm{~h}$ period ${ }^{(56)}$. Therefore, it remains inconclusive whether endogenous PYY levels do in fact make an impact on food intake.

Despite the lack of evidence on the regulation of endogenous PYY levels on food intake, in gastric-bypass patients, postprandial PYY levels are attenuated in those with poor weight loss compared with patients with good weight loss, suggesting an important role for PYY in the regulation of appetite ${ }^{(57)}$. Further, inhibiting PYY results in an increase in both appetite and food intake in human subjects $^{(57)}$. Finally, fasting PYY levels have been negatively correlated with BMI and waist circumference, which suggests a relationship between PYY and energy intake or overall energy homeostasis ${ }^{(56)}$.

Based on the overwhelming evidence on the impact of PYY in the ARC to control food intake, the effectiveness of exogenous PYY on decreasing food intake and body weight, and the relationship between endogenous PYY levels and body weight, this hormone does have an important role in appetite control. However, the fact that higher endogenous PYY levels do not always correspond to lower levels of food intake nor do they always correlate with subjective ratings of hunger and fullness highlights the fact that PYY alone is not responsible for appetite control. Overall appetite control is probably influenced by PYY, other acute hunger and satiety hormones, long-term adiposity signals (such as insulin and leptin), gut mechanoreceptors, visual and olfactory input, socio-economic factors, and food reward and memory ${ }^{(58)}$. Therefore, PYY is just one important piece to the complex puzzle that makes up appetite control.

\section{Peptide YY levels in non-obese $v$. obese}

Fasting PYY levels correlate negatively with $\mathrm{BMI}^{(25,59)}$, as levels in obese individuals are lower in the fasting state compared with non-obese individuals ${ }^{(60)}$. This has been shown in both adults ${ }^{(25)}$ and children ${ }^{(61)}$. Further, secretion of PYY following a meal has also been shown to be lower in obese subjects as compared with lean subjects ${ }^{(25,62)}$. This holds true even if obese subjects consume more food from a buffet meal than lean counterparts ${ }^{(25)}$. It has also been shown that weight loss leads to an increase in PYY, suggesting that weight loss can restore PYY levels ${ }^{(61)}$. Combined, these studies implicate that there may be a PYY deficiency in the pathogenesis of obesity or that an altered PYY phenotype exists following the onset of obesity. However, obesity does not appear to be associated with PYY resistance as is the case for leptin. PYY infusions in obese subjects result in a similar percentage reduction in food intake as compared with lean subjects. The mechanism(s) by which obese individuals have an altered PYY profile remain unknown. It could be the result of abnormalities in its synthesis, release, and/or clearance ${ }^{(25)}$; however, more work in needed to determine the causes for altered PYY fasting and postprandial profiles in obese individuals.

To complicate this association between weight status and PYY levels, some studies have shown no relationship between BMI or body weight and PYY levels ${ }^{(63,64)}$. It has been reported that weight loss in obese adolescents did not lead to changes in fasting PYY levels ${ }^{(65)}$. Kim et al. ${ }^{(63)}$ also reported that fasting PYY was not correlated with body weight, and PYY AUC was not different between lean and obese older adults following an oral glucose tolerance test. While it is unknown what causes the discrepancies between studies on the relationship between fasting PYY and BMI, the type of test meal incorporated in studies may have an impact on postprandial responses. In studies where differences were seen between obese and lean participants, mixed meals were used ${ }^{(25,62)}$. Conversely, the study by Kim et al. ${ }^{(63)}$, where there were no differences in PYY based on body weight, used an oral glucose tolerance test. It has also been shown that a greater postprandial PYY for normal-weight $v$. obese subjects exists for high-fat test meals, but not for highprotein or high-carbohydrate test meals ${ }^{(66)}$. Therefore, the presence of dietary fat may be necessary to show differences in postprandial PYY levels based on weight status. It has been shown that fat components directly stimulate L-cell secretion through activation of G-protein coupled receptor (GPR)-120 receptors. It is possible that in obese individuals, GPR-120 receptors are downregulated to fat stimulation, which would decrease PYY secretion $^{(67)}$.

Interestingly, one study has even reported that $\mathrm{PYY}_{3-36}$ levels were positively associated with BMI and waist circumference. This statistically significant correlation was weak ( $r 0 \cdot 158)$, and when participants were put into tertiles based on PYY levels, the BMI levels between the tertiles were quite small (range $\left.27 \cdot 8-29 \cdot 5 \mathrm{~kg} / \mathrm{m}^{2}\right)^{(68)}$. Clearly more research is needed to fully understand the relationship between body-weight status and both fasting and postprandial PYY levels. Additionally, although there 
appears to be some effect of body-weight status on PYY levels, it remains to be shown what the mechanism is behind that effect. There may be a genetic component, since plasma PYY was shown to be highly heritable in a phenotyped twin sample. A genetic pleiotropy was also found between PYY levels and BMI, suggesting that genetic variation at the PYY locus may influence weight status and other heritable metabolic syndrome traits ${ }^{(69)}$.

\section{Peptide YY as a therapeutic target for obesity}

Because of its well-known role in appetite regulation, PYY analogues are a therapeutic target for weight loss and weight management. Many initially thought that exogenous PYY administration could lead to a potential cure for the obesity epidemic. Indeed, exogenous administration of $\mathrm{PYY}_{3-36}$ has been shown to reduce body weight and adiposity in normal-weight and obese rodents fed a highfat diet ${ }^{(70,71)}$. Additionally, PYY transgenic mice that are crossed with ob/ob (genetically obese) mice exhibit lower body weights and adiposity ${ }^{(72)}$. There are currently two main issues decreasing the potential for PYY analogues to be effective as a therapeutic target for weight loss. The first issue is the severe gastrointestinal side effects that have been reported with moderate doses up to supraphysiological doses of $\mathrm{PYY}_{3-36}{ }^{(73,74)}$, which greatly limits its impact as a therapeutic target for obesity. The other issue deals with the method of administration. Oral ingestion of the hormone is not absorbed well and some argue that subcutaneous injections are not as effective because they are not directly stimulating the L-cells of the gastrointestinal tract ${ }^{(58)}$. Steinert et al. ${ }^{(75)}$ more recently reported successful absorption of oral administration of $\mathrm{PYY}_{3-36}$ with sodium N-caprylate in adult human subjects. Unfortunately, acute and $24 \mathrm{~h}$ energy intake was unchanged by the PYY administration, which again limits its potential as a therapeutic target to treat obesity. Therefore, slow progress is being made on the therapeutic front, but many roadblocks still remain. It is also important to recognise that overall energy homeostasis is influenced by a number of parameters and one single hormone is unlikely to be sufficient to permanently alter energy balance.

\section{Effects of exercise on peptide $Y Y$}

In the past 3 to 4 years, a number of studies have emerged assessing PYY responses to exercise. We, and others, have shown that acute aerobic exercise (ranging from low to high intensity) results in higher circulating plasma PYY levels ${ }^{(52,76-80)}$. While one recent study found no differences in post-exercise PYY for either continuous aerobic exercise or intermittent exercise compared with sedentary conditions $^{(81)}$, most studies show acute increases in PYY levels. Further, this increase appears to be intensity dependent, as greater exercise intensity leads to greater circulating PYY levels ${ }^{(82)}$. One study showed that steady-state and high-intensity intermittent exercise both raised postexercise PYY; however, PYY in the hours following exercise were highest following the high-intensity intermittent exercise ${ }^{(83)}$. Resistance exercise also acutely increases PYY levels, albeit in a lesser magnitude than aerobic exercise of similar energy output. Further, subjective scores of hunger during both aerobic and resistance exercise are reduced $^{(84)}$. The increase in PYY following exercise is only an acute response. There is no chronic adaptation to long-term exercise training. This was shown by the lack of change in fasting PYY levels after both aerobic training and resistance training regimens ${ }^{(85)}$.

Increased PYY levels as the result of aerobic exercise have also been shown to reduce subsequent energy intake in both lean and obese individuals, indicating an even greater protective effect against weight gain ${ }^{(86)}$. Still other studies have shown no differences in energy intake (or even slight increases in energy intake) when comparing post-exercise $v$. sedentary conditions. Importantly, however, if one takes into account the energy expended during exercise, there is still a greater negative energy balance in those studies exhibiting greater post-exercise PYY levels ${ }^{(79)}$.

A few studies have also examined the effects of chronic aerobic exercise. One challenge to these studies is the fact that weight loss usually occurs, making it difficult to determine whether changes in PYY are due to the exercise, weight loss, or a combination of the two. In obese adolescents, exercise training increased fasting PYY levels; however, some loss in fat mass also occurred which could at least partially explain the changes in PYY concentrations ${ }^{(87)}$. Conversely, a study in obese adults who performed aerobic training for $15 \mathrm{~d}$ revealed no differences in fasting or postprandial PYY levels from before to after the training intervention ${ }^{(88)}$. Yet another study showed no significant differences in PYY responses to an acute bout of exercise following a 12-week aerobic exercise programme. There was a trend $(P=0.06)$ for higher PYY values post-training; however, significant loss of body weight also occurred in this study ${ }^{(82)}$. Similarly, a 3-month weight-loss intervention (that included exercise) did not result in any changes to fasting, $24 \mathrm{~h}$ or postprandial PYY levels in previously sedentary adult women ${ }^{(89)}$. Probably the best study to elucidate the effects of chronic exercise independent of weight loss was done by Scheid et $a l .{ }^{(90)}$ where they showed that fasting PYY did not change following a 3-month exercise intervention in the absence of weight loss. Therefore, it appears that the effect of exercise on PYY is an acute response and that independent of changes in body weight, PYY levels do not change with chronic exercise training.

\section{Effects of ethnicity, sex and age on peptide YY levels}

Since weight status appears to influence PYY levels, investigators have explored whether circulating levels of PYY, 
either in the fasting or postprandial state, differ based on sex, ethnicity or age. To date, the research on race comparisons has been done in Caucasian and African-American individuals. One study in prepubertal children showed that fasting PYY, and PYY following an oral glucose tolerance test, were lower in African-American compared with Caucasian children ${ }^{(91)}$. Similarly, studies in adults also point toward reduced PYY levels in African-American individuals. One study examining both weight status (obese $v$. normal weight) and race reported no differences in fasting PYY levels between normal-weight or obese African-American $v$. Caucasian women. However, postprandial PYY levels were lower in obese African-American women compared with normal-weight African-American women, and both normal-weight and obese Caucasian women $^{(92)}$. Finally, another study comparing AfricanAmerican $v$. Caucasian women (matched for age and BMI) showed that both fasting and postprandial PYY levels were significantly lower in the African-American compared with Caucasian groups. Further, the change in PYY from baseline to $8 \mathrm{~h}$ postprandial was also lower in the African-American subjects $^{(93)}$. Together, these studies suggest that the PYY meal response is blunted in African-American compared with Caucasian women and that fasting PYY levels may also be lower. Since African-American women have a higher rate of obesity compared with Caucasian women in the USA ${ }^{(94,95)}$, understanding the reason behind these differences in PYY could make an impact on future therapeutic targets in African-American populations.

Several studies have explored the possibility of differences in fasting or postprandial PYY in humans based on sex, with conflicting results. One limitation in making comparisons between men and women is the fact that body weight and adiposity are generally not the same between the sexes and this may make an impact on differences in PYY, independent of sex. Indeed, one study showed that women had lower fasting and postprandial PYY levels ${ }^{(96)}$. However, the male subjects also weighed more and the PYY levels were not adjusted for body weight. Therefore, the elevated PYY levels may be due to the larger body weights in men $v$. women. Conversely, Kim et $a l^{(63)}$ found that while fasting PYY levels did not differ between men and women, postprandial PYY (AUC) after an oral glucose tolerance test was significantly higher in women compared with men. More recent studies have reported no differences in PYY based on sex. This lack of difference was reported for both resting and acute exercise conditions ${ }^{(97)}$, fasting conditions in normal-weight adults, even without adjustment for differences in body weight or adiposity ${ }^{(98)}$, and with fasting conditions in both lean and obese children ${ }^{(61)}$. Therefore, it appears that fasting PYY levels probably do not differ between men and women; however, there may be differences in acute meal responses. Whether postprandial PYY is higher or lower in men $v$. women remains to be determined and could be affected by the type of meal consumed as well as the weight status or amount of adiposity in the individuals.

Finally, ageing has been associated with a decrease in appetite $^{(99)}$ and a slowing of gastric emptying ${ }^{(100)}$. Since PYY may influence both of these, it was plausible to expect that there may be a role of ageing on circulating PYY levels and responses to nutrients. While CCK has been reported to be higher in older $v$. younger adults receiving an intraduodenal infusion of lipids and glucose, PYY does not appear to be affected by age ${ }^{(63,101)}$.

\section{Impact of macronutrients on peptide YY}

Postprandial PYY concentrations have been shown to be influenced by the macronutrient content of the meal. Unfortunately, at this time, the macronutrient resulting in the greatest PYY response is still being debated by some because it may be influenced by meal composition, obesity status, sex, and possibly age. Nearly all studies are in agreement that carbohydrates induce the smallest PYY response. The debate is whether dietary fats or dietary proteins elicit the greatest PYY response. Early research showed that dietary fat elicited the greatest PYY response ${ }^{(18)}$ while more recent studies have shown that protein results in the greatest PYY response ${ }^{(55)}$. It does appear that more studies support protein as a greater stimulator of PYY levels postprandially compared with fat. This has been shown in normal-weight and obese adults as well as obese adolescent females ${ }^{(55,66)}$. Importantly, subsequent energy intake and ratings of hunger are also lowest following a protein-rich meal $^{(55,66)}$. Another study in adolescents showed that the greatest and most sustained PYY response was found after a protein-rich meal followed by a fat-rich meal, and finally by a carbohydrate-rich meal in obese adolescents; however, the normal-weight adolescents responded most strongly to the fat-rich meal ${ }^{(102)}$. Therefore, in that study, weight status influenced the magnitude of PYY response to each macronutrient.

As mentioned above, it appears that both fat and protein elicit a greater postprandial PYY response compared with carbohydrates. One study in obese women during energy restriction reported greater PYY levels from high-protein $v$. high-carbohydrate meals. Unfortunately, this did not translate to differences in subjective hunger or fullness responses ${ }^{(53)}$. A single high-fat meal also resulted in greater postprandial PYY levels compared with a highcarbohydrate meal in obese women ${ }^{(103)}$. Further, a 1-week diet that was either low in carbohydrates (highfat) or high in carbohydrates (low-fat) led to a greater PYY response with the low-carbohydrate (high-fat) diet following test meals of identical composition ${ }^{(96)}$. This suggests that diets or single meals rich in dietary fat or protein induce a greater PYY response compared with diets or meals rich in carbohydrates. As mentioned above, however, weight status, and possibly age, may affect this response. A study in obese and normal-weight 
adolescent girls showed that normal-weight girls had a greater PYY response than obese girls to a high-fat meal while no differences between the groups were found following the high-carbohydrate meal ${ }^{(66)}$. This again points towards the impact that weight status may play on the magnitude of PYY response to different macronutrients. Additionally, the use of different fatty acids or sources of protein could explain some of the discrepancies about which macronutrient stimulates the greatest PYY response. This is explored more in subsequent paragraphs. Finally, all of the aforementioned studies examined acute meal responses. It does not appear that a chronic high-fat diet leads to any differences in fasting PYY levels when compared with a low-fat (high-carbohydrate) diet ${ }^{(104)}$.

It is also possible that the type of carbohydrate, fat or protein may influence the magnitude of PYY response. Very little research has been done on the type of protein and its effect on PYY release. Two studies in human subjects have reported no differences in the PYY response to a whey $v$. casein protein meal ${ }^{(105)}$ or whey $v$. both pea protein hydrolysate and a combined casein/whey milk protein (80\% casein, $20 \%$ whey $)^{(106)}$. Further, a 10-week feeding study in rats found no differences in plasma PYY levels between whey and soya protein diets ${ }^{(107)}$. Conversely, PYY mRNA was down-regulated in rats following a lifetime of a high-whey diet $v$. high-casein or high-soya diets ${ }^{(108)}$. Clearly, more studies are needed to determine the effects of different types of protein or amino acids on PYY levels in humans; however, initial work in human subjects and rats suggests no difference in circulating PYY levels based on different types of dietary protein.

With respect to carbohydrates, one study on glycaemic load and several studies on fibre have been published. The effect of a 1-week high- $v$. low-glycaemic-load diet was carried out in adult women. No effect was reported on either fasting or postprandial PYY levels ${ }^{(92)}$. The effects of fibre on PYY have been examined in both acute and long-term diet studies. The addition of wheat fibre to a carbohydrate-rich test meal resulted in a blunted postprandial PYY response compared with control, whereas oat fibre did not differ from the control meal ${ }^{(109)}$. Conversely, a pre-load of brown beans (higher in fibre) led to significantly higher fasting PYY levels and a greater PYY response at a test meal $10 \mathrm{~h}$ following the pre-load when compared with white wheat bread (lower in fibre) ${ }^{(110)}$. One long-term fibre supplementation study $(4 \mathrm{~g} / \mathrm{d}$ for 14 weeks) reported an increase in fasting PYY levels, while no differences in postprandial PYY levels were found $^{(111)}$. Similarly, 3 weeks of supplementing with 5-10 g of a fibre supplement per d led to higher fasting PYY levels in adult men and women ${ }^{(112)}$. Therefore, chronic intake of a fibre supplement or a higher-fibre diet appears to increase fasting PYY levels while postmeal responses following either acute meals or chronic feeding studies remain controversial.

\section{Dietary fatty acids and peptide YY}

While PYY has been shown to respond to dietary fats, little to no research exists on whether or not the composition of fatty acids can differentially influence PYY release. Only in the last few years has some research in this area emerged. Investigators have examined the form of fat (NEFA $v$. TAG), the chain length of fatty acids and saturation of fatty acids $^{(51,52,113,114)}$. In normal-weight men, NEFA administered intragastrically resulted in greater PYY levels than $\mathrm{TAG}^{(114)}$. With respect to chain length, intraduodenal infusions of either lauric acid (12:0) or capric acid (10:0) in healthy men showed that PYY levels were greater following 12 : 0 infusion compared with 10 : 0 and control, while 10 : 0 had no effect on PYY levels ${ }^{(115)}$. Additionally, another study showed that intraduodenal infusions of oleic acid (18: 1) led to a greater PYY response compared with lauric acid $(12: 0)^{(116)}$. Therefore, it appears that chain length is associated with PYY levels (the longer the chain length, the greater the PYY response).

With respect to fatty acid saturation, all of the studies have been done using long-chain fatty acids. Some previous research on subjective feelings of hunger and fullness indicate that fatty acids may influence overall hunger and satiety ${ }^{(52,117-120)}$. Lawton et al. ${ }^{(119)}$ reported that a meal rich in PUFA exerted the strongest control over appetite, based on subjective responses from visual analogue scale questionnaires as well as energy intake over the whole test day. Only four human studies to date have examined PYY responses to high-fat meals or high-fat diets rich in different fatty acids. These studies all examined fatty acid saturation, rather than chain length, on PYY responses. For the one high-fat diet study, we showed that a $3 \mathrm{~d}$ high-fat diet rich in SFA resulted in higher postprandial PYY levels compared with a high-fat diet rich in MUFA in normal-weight men ${ }^{(52)}$. This was only found after an evening meal, and $24 \mathrm{~h}$ measures of PYY did not differ between the diets. Additionally, these effects were found only in conjunction with daily aerobic exercise.

The other three remaining studies examined an acute or single high-fat meal response. Maljaars et al. ${ }^{(121)}$ reported no differences in PYY levels in normal-weight adults (men and women) following infusions of MUFA, PUFA or SFA. It is important to note that these were infusions of fatty acids via a naso-ileal catheter and not oral consumption of foods containing those fatty acids. Conversely, Robertson et $a l .^{(122)}$ studied oral consumption of high-fat meals rich in either SFA, MUFA or PUFA. They showed a trend for both SFA- and PUFA-rich meals to stimulate a greater PYY response compared with a MUFA-rich meal in postmenopausal women ${ }^{(122)}$. Finally, we recently showed that in normal-weight, premenopausal women, postprandial PYY levels were significantly higher for high-fat meals rich in PUFA and SFA compared with MUFA $^{(51)}$. Based on the evidence published so far, it appears that the fatty acid composition of a meal or diet 
may influence the magnitude of postprandial PYY responses, and that PUFA and SFA induce a greater PYY response compared with MUFA. Since MUFA are considered more 'heart healthy' than SFA, this information could have significant implications for public health recommendations. If MUFA are promoted over SFA, it may be important to suggest including these fats with foods that may have a greater impact on satiety, such as lean sources of protein or fibre in order to prevent overconsumption.

\section{Mechanisms behind the role of fatty acid composition on peptide YY levels}

Since research on the significant effects of dietary fatty acid composition on postprandial PYY levels in human subjects has only recently been published, little to no information exists on the mechanisms behind these effects. Because PYY release is affected by CCK levels ${ }^{(29)}$, it is possible that the effect of fatty acid composition on PYY is an indirect one through CCK. In the study mentioned above by Robertson et al. ${ }^{(122)}$ it was shown that peak CCK release after a high-fat meal challenge was greatest with a meal rich in SFA compared with either MUFA or PUFA. Since CCK does influence PYY release, greater CCK following a SFA-rich meal may be at least one of the mechanisms behind the greater PYY levels that we reported for SFA- $v$. MUFA-rich high-fat meals ${ }^{(51)}$.

Another hypothesis is related to the rate of digestion and absorption of different long-chain fatty acids. It has been shown in some very early studies that oils higher in MUFA and PUFA are absorbed more quickly than oils rich in SFA ${ }^{(123-126)}$. While the present study was carried out in rodents, a human study showed support for slower absorption of SFA-rich high-fat meals compared with MUFA- or PUFA-rich meals based on postprandial chylomicron appearance in plasma ${ }^{(127)}$. A slower absorption rate for SFA would mean that these fatty acids would be in contact with the endocrine L-cells that release PYY for longer periods of time. Therefore, the absorption rate of different fatty acids could probably affect the magnitude of PYY response. Since both of the aforementioned hypotheses have not been exclusively shown to be true, more work is needed to fully elucidate the mechanisms behind the differential PYY response to different dietary fatty acids. Additionally, more research is needed to see if the differences we reported in normal-weight, premenopausal women persist in other populations, such as males, obese individuals, and adolescents or children.

\section{Future direction}

Despite the fact that there are literally hundreds of studies that have been published on PYY, very little is known about the mechanisms by which nutrient ingestion stimulates the release of PYY from the enteroendocrine L-cells of the gastrointestinal tract. Some of the hypotheses mentioned above regarding the mechanisms behind different PYY responses to various dietary fatty acids may also be appropriate for other nutrients. It is known that CCK affects PYY release, although the exact mechanism behind this regulation is not clear ${ }^{(29)}$. It has also been shown that dietary fat can directly stimulate PYY secretion from the L-cells through activation of GPR-120 receptors ${ }^{(67)}$. Whether there are other proteins or hormones that can directly interact with the L-cells to release PYY remains to be determined. Additionally, we mentioned above that the length of time that nutrients are in contact with the L-cells influences the degree of PYY release; however, this has not been conclusively shown ${ }^{(51)}$. Therefore, there is a need for more research to elucidate the mechanisms by which nutrients affect the release of PYY as well as the factors that influence the magnitude of PYY release independent of total energy consumption. Finally, our recent findings on the differential release of PYY in response to high-fat meals rich in different fatty acids opens up a new avenue for research. Previous studies have focused on how macronutrients (carbohydrates, fats and proteins) influence PYY response, with little thought as to the type of carbohydrate, fat or protein being tested. More research on the influence of different dietary sources or types of carbohydrates, fats or proteins on PYY levels is warranted.

\section{Conclusion}

Great progress in understanding the role of PYY as a satiety hormone and its influence on energy homeostasis has occurred in the last 30 years. Further, we now know more about the other actions of PYY in the body, how exercise and different foods or nutrients affect PYY levels, and how age, sex, ethnicity and weight status can make an impact on PYY levels. Since obesity continues to be an epidemic of great concern in the USA and worldwide, additional research on the possibilities of using PYY as a therapeutic target for obesity without the negative side effects is warranted. However, as mentioned above, there are challenges facing the therapeutic potential of PYY given that the common side effect of PYY administration is nausea and that there are a number of hunger and satiety signals that probably influence overall energy intake. Therefore, future studies should explore if chronic, low doses of PYY can be effective at reducing food intake over time without the negative side effects as well as the development of a way to administer PYY in order to bypass the negative gastrointestinal issues that currently occur. Future work on other pharmacological, nutrient and dietary options as a potential way to alter PYY levels, and possibly energy intake, should also be explored. Finally, the mechanisms behind the release of PYY following nutrient ingestion and how different types of fatty acids, proteins or carbohydrates can affect the magnitude of release need to be studied further. 


\section{Acknowledgements}

There were no sources of funding for the present review, nor were there any sponsors. J. C. was solely responsible for formulating the research questions, selecting and reviewing the relevant literature, and preparing the manuscript. There were no conflicts of interest.

\section{References}

1. Ogden CL, Carroll MD, Curtin LR, et al. (2006) Prevalence of overweight and obesity in the United States, 1999-2004. JAMA 295, 1549-1555.

2. Ogden CL, Carroll MD, Kit BK, et al. (2013) Prevalence of obesity among adults: United States, 2011-2012. NCHS Data Brief, no. 131.

3. Wang YC, McPherson K, Marsh T, et al. (2011) Health and economic burden of the projected obesity trends in the USA and the UK. Lancet 378, 815-825.

4. von Ruesten A, Steffen A, Floegel A, et al. (2011) Trend in obesity prevalence in European adult cohort populations during follow-up since 1996 and their predictions to 2015. PLOS ONE 6, e27455.

5. Bogers RP, Bemelmans WJ, Hoogenveen RT, et al. (2007) Association of overweight with increased risk of coronary heart disease partly independent of blood pressure and cholesterol levels: a meta-analysis of 21 cohort studies including more than 300000 persons. Arch Intern Med 167, 1720-1728.

6. Vongpatanasin W (2007) Cardiovascular morbidity and mortality in high-risk populations: epidemiology and opportunities for risk reduction. J Clin Hypertens (Greenwich) 9, 11-15.

7. Steyn NP, Mann J, Bennett PH, et al. (2004) Diet, nutrition and the prevention of type 2 diabetes. Public Health Nutr 7, $147-165$.

8. Flatt JP (1987) The difference in the storage capacities for carbohydrate and for fat, and its implications in the regulation of body weight. Ann N Y Acad Sci 499, 104-123.

9. Hall KD, Sacks G, Chandramohan D, et al. (2011) Quantification of the effect of energy imbalance on bodyweight. Lancet 378, 826-837.

10. Levitsky DA (2005) The non-regulation of food intake in humans: hope for reversing the epidemic of obesity. Physiol Behav 86, 623-632.

11. Ogden CL, Fryar CD, Carroll MD, et al. (2004) Mean body weight, height, and body mass index, United States 1960 2002. Adv Data 347, 1-17.

12. Schoeller DA (2014) The effect of holiday weight gain on body weight. Physiol Behav (epublication ahead of print version 21 March 2014).

13. Beglinger C \& Degen L (2004) Fat in the intestine as a regulator of appetite - role of CCK. Physiol Behav 83, 617-621.

14. Druce MR, Small CJ \& Bloom SR (2004) Minireview: gut peptides regulating satiety. Endocrinology 145, 2660-2665.

15. Tatemoto K \& Mutt V (1980) Isolation of two novel candidate hormones using a chemical method for finding naturally occurring polypeptides. Nature 285, 417-418.

16. Stanley BG, Kyrkouli SE, Lampert S, et al. (1986) Neuropeptide $\mathrm{Y}$ chronically injected into the hypothalamus: a powerful neurochemical inducer of hyperphagia and obesity. Peptides 7, 1189-1192.

17. Broome M \& Hokfelt $\mathrm{T}$ (1985) Terenius L Peptide YY (PYY)-immunoreactive neurons in the lower brain stem and spinal cord of rat. Acta Physiol Scand 125, 349-352.
18. Adrian TE, Savage AP, Sagor GR, et al. (1985) Effect of peptide YY on gastric, pancreatic, and biliary function in humans. Gastroenterology 89, 494-499.

19. Batterham RL \& Bloom SR (2003) The gut hormone peptide YY regulates appetite. Ann N Y Acad Sci 994, $162-168$

20. Medeiros MD \& Turner AJ (1994) Processing and metabolism of peptide-YY: pivotal roles of dipeptidylpeptidase-IV, aminopeptidase-P, and endopeptidase-24.11. Endocrinology 134, 2088-2094.

21. Karra E, Chandarana K \& Batterham RL (2009) The role of peptide YY in appetite regulation and obesity. J Physiol $\mathbf{5 8 7}, 19-25$.

22. Grandt D, Schimiczek M, Beglinger C, et al. (1994) Two molecular forms of peptide YY (PYY) are abundant in human blood: characterization of a radioimmunoassay recognizing PYY 1-36 and PYY 3-36. Regul Pept 51, 151-159.

23. Maljaars PW, Peters HP, Mela DJ, et al. (2008) Ileal brake: a sensible food target for appetite control. A review. Physiol Behav 95, 271-281.

24. Batterham RL, Cowley MA, Small CJ, et al. (2002) Gut hormone PYY(3-36) physiologically inhibits food intake. Nature 418, 650-654.

25. Batterham RL, Cohen MA, Ellis SM, et al. (2003) Inhibition of food intake in obese subjects by peptide YY3-36. $N$ Engl J Med 349, 941-948.

26. Ko BS, Han JH, Jeong JI, et al. (2011) Mechanism of action of cholecystokinin on colonic motility in isolated, vascularly perfused rat colon. J Neurogastroenterol Motil 17, 73-81.

27. Gomez G, Padilla L, Udupi V, et al. (1996) Regulation of peptide YY homeostasis by gastric acid and gastrin. Endocrinology 137, 1365-1369.

28. Oh NG, Son GM, Sin JY, et al. (2005) Time-course of morphologic changes and peptide YY adaptation in ileal mucosa after loop ileostomy in humans. Dis Colon Rectum 48, 1287-1294.

29. Degen L, Drewe J, Piccoli F, et al. (2007) Effect of CCK-1 receptor blockade on ghrelin and PYY secretion in men. Am J Physiol Regul Integr Comp Physiol 292, R1391-R1399.

30. Oesch S, Ruegg C, Fischer B, et al. (2006) Effect of gastric distension prior to eating on food intake and feelings of satiety in humans. Physiol Behav 87, 903-910.

31. Adrian TE, Ferri GL, Bacarese-Hamilton AJ, et al. (1985) Human distribution and release of a putative new gut hormone, peptide YY. Gastroenterology 89, 1070-1077.

32. Ford HE, Peters V, Martin NM, et al. (2011) Effects of oral ingestion of sucralose on gut hormone response and appetite in healthy normal-weight subjects. Eur J Clin Nutr 65, 508-513.

33. Onaga T, Zabielski R \& Kato S (2002) Multiple regulation of peptide YY secretion in the digestive tract. Peptides $\mathbf{2 3}$, 279-290.

34. Feinle-Bisset C, Patterson M, Ghatei MA, et al. (2005) Fat digestion is required for suppression of ghrelin and stimulation of peptide YY and pancreatic polypeptide secretion by intraduodenal lipid. Am J Physiol Endocrinol Metab 289, E948-E953.

35. Greenberg JA \& Geliebter A (2012) Coffee, hunger, and peptide YY. J Am Coll Nutr 31, 160-166.

36. Calissendorff J, Danielsson O, Brismar K, et al. (2006) Alcohol ingestion does not affect serum levels of peptide YY but decreases both total and octanoylated ghrelin levels in healthy subjects. Metabolism 55, 1625-1629.

37. Suzuki K, Jayasena CN \& Bloom SR (2012) Obesity and appetite control. Exp Diabetes Res 2012, 824305. 
38. Cowley MA, Cone R, Enriori P, et al. (2003) Electrophysiological actions of peripheral hormones on melanocortin neurons. Ann N Y Acad Sci 994, 175-186.

39. Cone RD, Cowley MA, Butler AA, et al. (2001) The arcuate nucleus as a conduit for diverse signals relevant to energy homeostasis. Int J Obes Relat Metab Disord 25, Suppl. 5, S63-S67.

40. Suzuki K, Simpson KA, Minnion JS, et al. (2010) The role of gut hormones and the hypothalamus in appetite regulation. Endocr J 57, 359-372.

41. Schwartz MW, Woods SC, Porte D Jr, et al. (2000) Central nervous system control of food intake. Nature $\mathbf{4 0 4}$, 661-671.

42. Sainsbury A, Cooney GJ \& Herzog H (2002) Hypothalamic regulation of energy homeostasis. Best Pract Res Clin Endocrinol Metab 16, 623-637.

43. Ingenhoven N, Eckard CP, Gehlert DR, et al. (1999) Molecular characterization of the human neuropeptide $\mathrm{Y}$ Y2-receptor. Biochemistry 38, 6897-6902.

44. Tovar SA, Seoane LM, Caminos JE, et al. (2004) Regulation of peptide YY levels by age, hormonal, and nutritional status. Obes Res 12, 1944-1950.

45. Acuna-Goycolea C \& van den Pol AN (2005) Peptide YY $_{3-36}$ inhibits both anorexigenic proopiomelanocortin and orexigenic neuropeptide Y neurons: implications for hypothalamic regulation of energy homeostasis. J Neurosci 25, 10510-10519.

46. Challis BG, Coll AP, Yeo GS, et al. (2004) Mice lacking pro-opiomelanocortin are sensitive to high-fat feeding but respond normally to the acute anorectic effects of peptide-YY(3-36). Proc Natl Acad Sci U S A 101, 4695-4700.

47. Le Roux CW, Batterham RL, Aylwin SJ, et al. (2006) Attenuated peptide YY release in obese subjects is associated with reduced satiety. Endocrinology 147, 3-8.

48. Degen L, Oesch S, Casanova M, et al. (2005) Effect of peptide YY3-36 on food intake in humans. Gastroenterology 129, 1430-1436.

49. Gutzwiller JP, Goke B, Drewe J, et al. (1999) Glucagon-like peptide-1: a potent regulator of food intake in humans. Gut 44, 81-86.

50. Flint A, Raben A, Astrup A, et al. (1998) Glucagon-like peptide 1 promotes satiety and suppresses energy intake in humans. J Clin Invest 101, 515-520.

51. Kozimor A, Chang H \& Cooper JA (2013) Effects of dietary fatty acid composition from a high fat meal on satiety. Appetite 69, 39-45.

52. Cooper JA, Watras AC, Paton CM, et al. (2011) Impact of exercise and dietary fatty acid composition from a high-fat diet on markers of hunger and satiety. Appetite 56, $171-178$.

53. Heden TD, Liu Y, Sims L, et al. (2013) Liquid meal composition, postprandial satiety hormones, and perceived appetite and satiety in obese women during acute caloric restriction. Eur J Endocrinol 168, 593-600.

54. Livingstone MB, Robson PJ, Welch RW, et al. (2000) Methodological issues in the assessment of satiety. Scand J Nutr 44, 98-103.

55. Batterham RL, Heffron H, Kapoor S, et al. (2006) Critical role for peptide YY in protein-mediated satiation and body-weight regulation. Cell Metab 4, 223-233.

56. Guo J, Ma L, Enriori PJ, et al. (2006) Physiological evidence for the involvement of peptide YY in the regulation of energy homeostasis in hu. Obesity (Silver Spring) 14, $1562-1570$.

57. Le Roux CW, Welbourn R, Werling M, et al. (2007) Gut hormones as mediators of appetite and weight loss after Roux-en-Y gastric bypass. Ann Surg 246, 780-785.
58. De Silva A \& Bloom SR (2012) Gut hormones and appetite control: a focus on PYY and GLP-1 as therapeutic targets in obesity. Gut Liver 6, 10-20.

59. Ashby D \& Bloom SR (2007) Recent progress in PYY research - an update report for 8th NPY meeting. Peptides 28, 198-202.

60. Alvarez BM, Borque M, Martinez-Sarmiento J, et al. (2002) Peptide YY secretion in morbidly obese patients before and after vertical banded gastroplasty. Obes Surg 12, 324-327.

61. Roth CL, Enriori PJ, Harz K, et al. (2005) Peptide YY is a regulator of energy homeostasis in obese children before and after weight loss. J Clin Endocrinol Metab 90, 6386-6391.

62. Stock S, Leichner P, Wong AC, et al. (2005) Ghrelin, peptide YY, glucose-dependent insulinotropic polypeptide, and hunger responses to a mixed meal in anorexic, obese, and control female adolescents. J Clin Endocrinol Metab 90, 2161-2168.

63. Kim BJ, Carlson OD, Jang HJ, et al. (2005) Peptide YY is secreted after oral glucose administration in a genderspecific manner. J Clin Endocrinol Metab 90, 6665-6671.

64. Vazquez Roque MI, Camilleri M, Stephens DA, et al. (2006) Gastric sensorimotor functions and hormone profile in normal weight, overweight, and obese people. Gastroenterology 131, 1717-1724.

65. Gueugnon C, Mougin F, Nguyen NU, et al. (2012) Ghrelin and PYY levels in adolescents with severe obesity: effects of weight loss induced by long-term exercise training and modified food habits. Eur J Appl Physiol 112, 1797-1805.

66. Misra M, Tsai PM, Mendes N, et al. (2009) Increased carbohydrate induced ghrelin secretion in obese vs. normalweight adolescent girls. Obesity (Silver Spring) 17, $1689-1695$

67. Hirasawa A, Tsumaya K, Awaji T, et al. (2005) Free fatty acids regulate gut incretin glucagon-like peptide- 1 secretion through GPR120. Nat Med 11, 90-94.

68. Ukkola OH, Puurunen VP, Piira OP, et al. (2011) High serum fasting peptide YY $(3-36)$ is associated with obesity-associated insulin resistance and type 2 diabetes. Regul Pept 170, 38-42.

69. Shih PA, Wang L, Chiron S, et al. (2009) Peptide YY (PYY) gene polymorphisms in the $3^{\prime}$-untranslated and proximal promoter regions regulate cellular gene expression and PYY secretion and metabolic syndrome traits in vivo. J Clin Endocrinol Metab 94, 4557-4566

70. Pittner RA, Moore CX, Bhavsar SP, et al. (2004) Effects of PYY[3-36] in rodent models of diabetes and obesity. Int J Obes Relat Metab Disord 28, 963-971.

71. Chelikani PK, Haver AC \& Reidelberger RD (2007) Intermittent intraperitoneal infusion of peptide $\mathrm{YY}(3-36)$ reduces daily food intake and adiposity in obese rats. Am J Physiol Regul Integr Comp Physiol 293, R39-R46.

72. Boey D, Lin S, Enriquez RF, et al. (2008) PYY transgenic mice are protected against diet-induced and genetic obesity. Neuropeptides $\mathbf{4 2}, 19-30$.

73. Le Roux CW, Borg CM, Murphy KG, et al. (2008) Supraphysiological doses of intravenous PYY3-36 cause nausea, but no additional reduction in food intake. Ann Clin Biochem 45, 93-95.

74. Gantz I, Erondu N, Mallick M, et al. (2007) Efficacy and safety of intranasal peptide YY3-36 for weight reduction in obese adults. J Clin Endocrinol Metab 92 , $1754-1757$

75. Steinert RE, Poller B, Castelli MC, et al. (2010) Oral administration of glucagon-like peptide 1 or peptide YY 3-36 affects food intake in healthy male subjects. Am J Clin Nutr 92, 810-817. 
76. Martins C, Morgan LM, Bloom SR, et al. (2007) Effects of exercise on gut peptides, energy intake and appetite. $J$ Endocrinol 193, 251-258.

77. Kawano H, Mineta M, Asaka M, et al. (2013) Effects of different modes of exercise on appetite and appetiteregulating hormones. Appetite 66, 26-33.

78. Deighton K, Barry R, Connon CE, et al. (2013) Appetite, gut hormone and energy intake responses to low volume sprint interval and traditional endurance exercise. Eur $J$ Appl Physiol 113, 1147-1156.

79. Larson-Meyer DE, Palm S, Bansal A, et al. (2012) Influence of running and walking on hormonal regulators of appetite in women. $J$ Obes 2012, 730409.

80. Wasse LK, Sunderland C, King JA, et al. (2012) Influence of rest and exercise at a simulated altitude of $4,000 \mathrm{~m}$ on appetite, energy intake, and plasma concentrations of acylated ghrelin and peptide YY. J Appl Physiol 112, 552-559.

81. Holmstrup ME, Fairchild TJ, Keslacy S, et al. (2013) Satiety, but not total PYY, is increased with continuous and intermittent exercise. Obesity (Silver Spring) 21, 2014-2020.

82. Ueda SY, Miyamoto T, Nakahara H, et al. (2013) Effects of exercise training on gut hormone levels after a single bout of exercise in middle-aged Japanese women. Springerplus 2, 83.

83. Deighton K, Karra E, Batterham RL, et al. (2013) Appetite, energy intake, and PYY3-36 responses to energy-matched continuous exercise and submaximal high-intensity exercise. Appl Physiol Nutr Metab 38, 947-952.

84. Broom DR, Batterham RL, King JA, et al. (2009) Influence of resistance and aerobic exercise on hunger, circulating levels of acylated ghrelin, and peptide $\mathrm{YY}$ in healthy males. Am J Physiol Regul Integr Comp Physiol 296, $\mathrm{R} 29-\mathrm{R} 35$.

85. Guelfi KJ, Donges CE \& Duffield R (2013) Beneficial effects of 12 weeks of aerobic compared with resistance exercise training on perceived appetite in previously sedentary overweight and obese men. Metabolism 62, 235-243.

86. Ueda SY, Yoshikawa T, Katsura Y, et al. (2009) Changes in gut hormone levels and negative energy balance during aerobic exercise in obese young males. J Endocrinol 203, 357-364.

87. Jones TE, Basilio JL, Brophy PM, et al. (2009) Long-term exercise training in overweight adolescents improves plasma peptide YY and resistin. Obesity (Silver Spring) 17, $1189-1195$.

88. Kanaley JA, Heden TD, Liu Y, et al. (2014) Short-term aerobic exercise training increases postprandial pancreatic polypeptide but not peptide YY concentrations in obese individuals. Int J Obes (Lond) 38, 266-271.

89. Hill BR, De Souza MJ, Wagstaff DA, et al. (2013) The impact of weight loss on the 24-h profile of circulating peptide YY and its association with 24 -h ghrelin in normal weight premenopausal women. Peptides 49, 81-90.

90. Scheid JL, De Souza MJ, Leidy HJ, et al. (2011) Ghrelin but not peptide $\mathrm{YY}$ is related to change in body weight and energy availability. Med Sci Sports Exerc 43, 2063-2071.

91. Bacha F \& Arslanian SA (2006) Ghrelin and peptide YY in youth: are there race-related differences? J Clin Endocrinol Metab 91, 3117-3122.

92. Brownley KA, Heymen S, Hinderliter AL, et al. (2010) Effect of glycemic load on peptide-YY levels in a biracial sample of obese and normal weight women. Obesity (Silver Spring) 18, 1297-1303.

93. Davis J, Hickner RC, Tanenberg RJ, et al. (2005) Peptide-YY levels after a fat load in black and white women. Obes Res 13, 2055-2057.
94. Centers for Disease Control (2010) Differences in prevalence of obesity among black, white, and Hispanic adults - United States, 2006-2008. MMWR 58, 740-744.

95. Flegal KM, Carroll MD, Kit BK, et al. (2012) Prevalence of obesity and trends in the distribution of body mass index among US adults, 1999-2010. JAMA 307, 491-497.

96. Essah PA, Levy JR, Sistrun SN, et al. (2007) Effect of macronutrient composition on postprandial peptide YY levels. J Clin Endocrinol Metab 92, 4052-4055.

97. Hagobian TA, Yamashiro M, Hinkel-Lipsker J, et al. (2013) Effects of acute exercise on appetite hormones and ad libitum energy intake in men and women. Appl Physiol Nutr Metab 38, 66-72.

98. St-Onge MP, O'Keeffe M, Roberts AL, et al. (2012) Short sleep duration, glucose dysregulation and hormonal regulation of appetite in men and women. Sleep 35, 1503-1510.

99. Wurtman JJ, Lieberman H, Tsay R, et al. (1988) Calorie and nutrient intakes of elderly and young subjects measured under identical conditions. J Gerontol 43, B174-B180.

100. Clarkston WK, Pantano MM, Morley JE, et al. (1997) Evidence for the anorexia of aging: gastrointestinal transit and hunger in healthy elderly vs. young adults. Am J Physiol 272, R243-R248.

101. MacIntosh CG, Andrews JM, Jones KL, et al. (1999) Effects of age on concentrations of plasma cholecystokinin, glucagon-like peptide 1 , and peptide YY and their relation to appetite and pyloric motility. Am J Clin Nutr 69, 999-1006.

102. Lomenick JP, Melguizo MS, Mitchell SL, et al. (2009) Effects of meals high in carbohydrate, protein, and fat on ghrelin and peptide YY secretion in prepubertal children. J Clin Endocrinol Metab 94, 4463-4471.

103. Helou N, Obeid O, Azar ST, et al. (2008) Variation of postprandial PYY 3-36 response following ingestion of differing macronutrient meals in obese females. Ann Nutr Metab 52, 188-195.

104. Little TJ, Feltrin KL, Horowitz M, et al. (2008) A high-fat diet raises fasting plasma CCK but does not affect upper gut motility, PYY, and ghrelin, or energy intake during CCK-8 infusion in lean men. Am J Physiol Regul Integr Comp Physiol 294, R45-R51.

105. Sukkar SG, Vaccaro A, Ravera GB, et al. (2013) Appetite control and gastrointestinal hormonal behavior (CCK, GLP-1, PYY 1-36) following low doses of a whey proteinrich nutraceutic. Med J Nutrition Metab 6, 259-266.

106. Diepvens K \& Haberer D (2008) Westerterp-Plantenga M Different proteins and biopeptides differently affect satiety and anorexigenic/orexigenic hormones in healthy humans. Int J Obes (Lond) 32, 510-518.

107. Zhou J, Keenan MJ, Losso JN, et al. (2011) Dietary whey protein decreases food intake and body fat in rats. Obesity (Silver Spring) 19, 1568-1573.

108. Xiao R, Badger TM \& Simmen FA (2005) Dietary exposure to soy or whey proteins alters colonic global gene expression profiles during rat colon tumorigenesis. Mol Cancer 4, 1.

109. Weickert MO, Spranger J, Holst JJ, et al. (2006) Wheat-fibreinduced changes of postprandial peptide YY and ghrelin responses are not associated with acute alterations of satiety. BrJ Nutr 96, 795-798.

110. Nilsson A, Johansson E, Ekstrom L, et al. (2013) Effects of a brown beans evening meal on metabolic risk markers and appetite regulating hormones at a subsequent standardized breakfast: a randomized cross-over study. PLOS ONE 8, e59985.

111. Greenway F, O'Neil CE, Stewart L, et al. (2007) Fourteen weeks of treatment with Viscofiber increased fasting levels of glucagon-like peptide-1 and peptide-YY. J Med Food 10, $720-724$. 
112. Reimer RA, Pelletier X, Carabin IG, et al. (2010) Increased plasma PYY levels following supplementation with the functional fiber PolyGlycopleX in healthy adults. Eur $J$ Clin Nutr 64, 1186-1191.

113. Little TJ, Horowitz M \& Feinle-Bisset C (2007) Modulation by high-fat diets of gastrointestinal function and hormones associated with the regulation of energy intake: implications for the pathophysiology of obesity. Am J Clin Nutr 86, 531-541.

114. Little TJ, Russo A, Meyer JH, et al. (2007) Free fatty acids have more potent effects on gastric emptying, gut hormones, and appetite than triacylglycerides. Gastroenterology 133, 1124-1131.

115. Feltrin KL, Patterson M, Ghatei MA, et al. (2006) Effect of fatty acid chain length on suppression of ghrelin and stimulation of PYY, GLP-2 and PP secretion in healthy men. Peptides 27, 1638-1643.

116. Feltrin KL, Little TJ, Meyer JH, et al. (2008) Comparative effects of intraduodenal infusions of lauric and oleic acids on antropyloroduodenal motility, plasma cholecystokinin and peptide YY, appetite, and energy intake in healthy men. Am J Clin Nutr 87, 1181-1187.

117. Casas-Agustench P, Lopez-Uriarte P, Bullo M, et al. (2009) Acute effects of three high-fat meals with different fat saturations on energy expenditure, substrate oxidation and satiety. Clin Nutr 28, 39-45.

118. Flint A, Helt B, Raben A, et al. (2003) Effects of different dietary fat types on postprandial appetite and energy expenditure. Obes Res 11, 1449-1455.
119. Lawton CL, Delargy HJ, Brockman J, et al. (2000) The degree of saturation of fatty acids influences post-ingestive satiety. Br J Nutr 83, 473-482.

120. Strik CM, Lithander FE, McGill AT, et al. (2010) No evidence of differential effects of SFA, MUFA or PUFA on postingestive satiety and energy intake: a randomised trial of fatty acid saturation. Nutr J 9, 24 .

121. Maljaars J, Romeyn EA, Haddeman E, et al. (2009) Effect of fat saturation on satiety, hormone release, and food intake. Am J Clin Nutr 89, 1019-1024.

122. Robertson MD, Jackson KG, Fielding BA, et al. (2002) Acute ingestion of a meal rich in $n-3$ polyunsaturated fatty acids results in rapid gastric emptying in humans. Am J Clin Nutr 76, 232-238

123. Steenbock H, Irwin MH \& Weber J (1936) The comparative rate of absorption of different fats. J Nutr 12, 103-111.

124. Holt PR \& Clark SB (1969) Dietary triglyceride composition related to intestinal fat absorption. Am J Clin Nutr $\mathbf{2 2}$ 279-283.

125. Feldman EB, Russell BS, Chen R, et al. (1983) Dietary saturated fatty acid content affects lymph lipoproteins: studies in the rat. $J$ Lipid Res 24, 967-976.

126. Hoagland R \& Snider GG (1943) Digestibility of some animal and vegetable fats. J Nutr 25, 295.

127. Jackson KG, Robertson MD, Fielding BA, et al. (2002) Olive oil increases the number of triacylglycerol-rich chylomicron particles compared with other oils: an effect retained when a second standard meal is fed. Am J Clin Nutr 76, 942-949. 